\title{
Osthole attenuates pulmonary arterial hypertension in monocrotaline-treated rats
}

\author{
YELI LI $^{1}$, YINGWAN WANG ${ }^{1}$, YIQI LI ${ }^{2}$, ZHIQIANG QIAN $^{1}$, LING ZHU $^{1}$ and DANLI YANG ${ }^{1}$ \\ ${ }^{1}$ Key Laboratory of Basic Pharmacology of Ministry of Education and Joint International Research \\ Laboratory of Ethnomedicine of Ministry of Education, Zunyi Medical University, Zunyi, Guizhou 563003; \\ ${ }^{2}$ Department of Pharmacology, Zunyi Medical University, Zhuhai, Guangdong 519041, P.R. China
}

Received May 23, 2016; Accepted April 19, 2017

DOI: $10.3892 / \mathrm{mmr} .2017 .6876$

\begin{abstract}
Pulmonary arterial hypertension (PAH) is an insidious and progressive disease that is triggered by various cardiopulmonary diseases. Inflammation has an important role in the progression of PAH. Osthole (Ost) is a coumarin that has clear anti-inflammatory properties. The present study aimed to investigate the effects of Ost on $\mathrm{PAH}$, and to explore the mechanism underlying this effect. Using the monocrotaline (MCT)-induced PAH rat model, the effects of Ost on PAH were investigated. Rats were subcutaneously administered a single dose of MCT $(50 \mathrm{mg} / \mathrm{kg})$ to establish the PAH model, followed by daily treatment with Ost $(10$ or $20 \mathrm{mg} / \mathrm{kg}$ ) by gavage for 28 days. The mean pulmonary arterial pressure (mPAP) was measured and histological analysis was performed. The results demonstrated that Ost significantly decreased mPAP, and reduced thickening of the pulmonary artery, compared with in rats in the MCT group. To further determine whether the effects of Ost on MCT-induced PAH were associated with inflammatory responses, the nuclear factor- $\kappa \mathrm{B}(\mathrm{NF}-\mathrm{\kappa B}) \mathrm{p} 65$ signaling pathway was investigated by western blot analysis. The results demonstrated that Ost increased inhibition of the NF- $\mathrm{BB}$ p65 signaling pathway. In conclusion, the results of the present study demonstrate that Ost may suppress the progression of MCT-induced PAH in rats, which may be, at
\end{abstract}

Correspondence to: Professor Danli Yang, Key Laboratory of Basic Pharmacology of Ministry of Education and Joint International Research Laboratory of Ethnomedicine of Ministry of Education, Zunyi Medical University, 6 Xuefuxi Road, Zunyi, Guizhou 563003, P.R. China

E-mail: zmuyangdanli@foxmail.com

Abbreviations: Ost, osthole; $\mathrm{PAH}$, pulmonary arterial hypertension; MCT, monocrotaline; mPAP, mean pulmonary arterial pressure; $\mathrm{NF}-\kappa \mathrm{B}$, nuclear factor- $\kappa \mathrm{B}$; I $\mathrm{IB} \alpha$, inhibitor of NF- $\kappa \mathrm{B} \alpha$; TNF, tumor necrosis factor; COX, cyclooxygenase; IL, interleukin; WT, wall thickness

Key words: osthole, monocrotaline, pulmonary arterial hypertension, nuclear factor- $\mathrm{\kappa B}$ p 65 least partially, mediated through modulation of the NF- $\kappa B$ p65 signaling pathway.

\section{Introduction}

Pulmonary arterial hypertension $(\mathrm{PAH})$ is a multifactorial disease characterized by a progressive increase of pulmonary artery pressure and pulmonary vascular resistance, which leads to right ventricle overload and hypertrophy, and subsequently to right ventricular dysfunction and right-sided heart failure $(1,2)$. At present, the pathogenesis of PAH remains unclear; it may involve numerous factors, including pulmonary artery endothelial dysfunction, inflammation, oxidative stress and mutation of the bone morphogenetic protein receptor, as well as the interaction of these factors (3-5). Among these factors, inflammation has an important role in the progression of PAH (3). The inflammatory processes are inextricably implicated in the vascular alterations associated with PAH (6). Previous studies have demonstrated that inflammation and immunological responses lead to endothelial cell injury and stimulate pulmonary arterial smooth muscle cell proliferation, resulting in pulmonary arterial remodeling and the acceleration of the development of PAH $(3,7)$. Notably, clinical and animal studies have demonstrated that advanced vascular remodeling may be reversed via the inhibition of specific inflammatory responses (3). Nuclear factor- $\kappa \mathrm{B}(\mathrm{NF}-\kappa \mathrm{B})$ is associated with inflammatory reactions, and the proliferation and apoptosis of eukaryotic cells (8). Inhibition of $\mathrm{NF}-\kappa \mathrm{B}$ decreases the expression of vascular cell adhesion molecule-1 and the infiltration of macrophages, and has previously been reported to improve pulmonary hypertension in a rat model of monocrotaline (MCT)-induced PAH (9), which indicates that the activation of $N F-\kappa B$ has an important role in the pathogenesis of PAH. Therefore, inhibition of $N F-\kappa B$ may represent a beneficial therapeutic strategy for $\mathrm{PAH}$.

Traditional treatments for PAH include the application of oxygen, anti-coagulant agents and calcium channel blockers. Current therapeutic strategies for reducing PAH focus on dilating the partially occluded vessels by utilizing phosphodiesterase type 5 inhibitors, endothelin receptor antagonists and prostanoids. However, current medications have certain limitations, for example, phosphodiesterase type 5 inhibitors are associated with renal damage and hypotension, endothelin 
receptor antagonists are expensive, and prostanoids have short half-lives and are difficult for oral administration. Although current therapies have an effect on $\mathrm{PAH}$, the prognosis of $\mathrm{PAH}$ and the survival rate remain poor $(7,10-12)$. Therefore, there is an urgency to develop novel drugs for PAH (13).

Osthole [Ost; 7-methoxy-8-(3-methyl-2-butenyl)] is a coumarin and an active constituent of Cnidium monnieri (L.) Cusson. Previous studies have revealed that Ost exhibits various pharmacological activities, including anti-inflammatory, antioxidative, antitumor, antiproliferative, vasodilative andimmunomodulatory properties (14-18). Ost has been demonstrated to alleviate inflammatory reactions in carrageenan-induced lung inflammation and renal ischemia-reperfusion injury in rats $(19,20)$. Therefore, the present study aimed to investigate the effects of Ost on MCT-induced PAH and to further investigate the potential mechanisms involved.

\section{Materials and methods}

Animals. Male Sprague-Dawley rats $(n=45$; age, 8 weeks; weight, 200-220 g; specific pathogen-free; certificate no. SCXK 2012-0005) were purchased from Animal Center of the Institute of Surgery Research of the Third Military Medical University (Chongqing, China). All rats were housed under standard conditions of constant temperature $\left(21-23^{\circ} \mathrm{C}\right)$, relative humidity (60-65\%) and a 12-h light/dark cycle. The rats had free access to chow and water. The rats were acclimated for 1 week prior to experimentation and were fasted overnight with free access to water prior to drug administration. All animal studies were performed in compliance with the Animal Care and Use Guidelines in China, and were approved by the Animal Use and Care Committee of Zunyi Medical University (Zunyi, China).

Drugs and reagents. Reagent grade Ost (purity $\geq 98 \%$ by high performance liquid chromatography; Nanjing Zelang Medical Technology Co., Ltd., Nanjing, China) was dissolved in double distilled water with $0.5 \%$ Tween-80. MCT (Sigma-Aldrich; Merck KGaA, Darmstadt, Germany) was dissolved in $0.5 \mathrm{M}$ hydrochloric acid and adjusted to $\mathrm{pH} 7.4$ with $0.5 \mathrm{M}$ sodium hydroxide and diluted with normal saline to a final concentration of $10 \mathrm{mg} / \mathrm{ml}$.

PAH model generation and drug administration. Rats $(\mathrm{n}=45)$ were randomly divided into four groups: Control group $(n=10)$, MCT group $(\mathrm{n}=15)$ and Ost treatment groups $\left(\mathrm{Ost}_{10}, 10 \mathrm{mg} / \mathrm{kg}\right.$ and $\mathrm{Ost}_{20}, 20 \mathrm{mg} / \mathrm{kg} ; \mathrm{n}=10 /$ group). All rats were given a single subcutaneous dose of $50 \mathrm{mg} / \mathrm{kg}$ MCT to establish the PAH model, with the exception of the rats in the control group. The control group rats were injected subcutaneously with $5 \mathrm{ml} / \mathrm{kg}$ normal saline instead of MCT. Subsequently, rats in the Ost treatment groups were treated with 10 or $20 \mathrm{mg} / \mathrm{kg}$ Ost orally by gavage, once a day from day 1 to day 28 . The control group and MCT group rats were administered volume-matched double distilled water with $0.5 \%$ Tween $-80(5 \mathrm{ml} / \mathrm{kg})$ orally by gavage instead of Ost.

Hemodynamic measurements. A total of 4 rats in the MCT group succumbed on days 14, 20,24 and 27, respectively. There were no further mortalities. All surviving rats were subjected to hemodynamic measurements. Mean pulmonary artery pressure (mPAP) was measured by right heart catheterization. Rats were anaesthetized with chloral hydrate $(0.35 \mathrm{~g} / \mathrm{kg}$; intraperitoneal) and a polyethylene catheter connected to a pressure transducer was then inserted into the right jugular vein, through the right atrium, right ventricle and finally to the pulmonary artery. Whether the polyethylene catheter had entered the pulmonary artery was determined by the basis of changes in the pressure waveform indicated on a monitor connected to a Powerlab system (PowerLab/8SP; AD Instruments Pty, Ltd., Sydney, NSW, Australia). Once the catheter had entered the pulmonary artery, mPAP was acquired.

Lung weight index measurements. Following hemodynamic measurements, all of the rats were sacrificed. Subsequently, the chest cavity of the rats was immediately opened, lungs were excised rapidly and placed into ice-cold normal saline for removal of blood, after which the lungs were blotted and weighed. Subsequently, lung weight index was calculated as the ratio of lung weight to body weight.

Hematoxylin and eosin $(H \& E)$ staining. The left pulmonary tissue was removed from the hilum and followed by post-fixing in $4 \%$ formaldehyde diluted with $0.1 \mathrm{M} \mathrm{PBS}(\mathrm{pH}=7.4)$ for $48 \mathrm{~h}$ at $4^{\circ} \mathrm{C}$ and embedding in paraffin. Tissue sections $(5 \mu \mathrm{m})$ were stained with $H \& E$. The H\&E staining was performed by staining with $0.5 \%$ hematoxylin for $3 \mathrm{~min}$, followed by $0.5 \%$ eosin staining for $2 \mathrm{~min}$ at room temperature, and the sections were subsequently dehydrated with graded ethanol $(70 \%$ ethanol, $15 \mathrm{sec}$; $80 \%$ ethanol, $15 \mathrm{sec}$; $90 \%$ ethanol, $20 \mathrm{sec}$; 95\% ethanol, $20 \mathrm{sec}$; anhydrous ethanol I, $20 \mathrm{sec}$; anhydrous ethanol II, $20 \mathrm{sec}$ ), rendered hyaline using xylene, and sealed. The H\&E stained slides were subsequently observed under a light microscope (Leica Microsystems GmbH, Wetzlar, Germany). The external diameter and wall thickness (WT) were measured by Image-Pro Plus 6.0 image analysis software (Media Cybernetics, Inc., Rockville, MD, USA) for muscular arteries of size ranges 50-100 $\mu \mathrm{m}$. A total of 6-7 muscular arteries from each group were evaluated. Percentage WT (\%WT), an index of medial hypertrophy, was calculated according to the following formula: $\% \mathrm{WT}=[(2 \mathrm{xWT}) /$ external diameter]x100 (21).

Western blot analysis. The protein expression of inhibitor of $\mathrm{NF}-\kappa \mathrm{B} \alpha(\mathrm{I} \kappa \mathrm{B} \alpha)$, tumor necrosis factor (TNF)- $\alpha$, cyclooxygenase (COX)-2, interleukin (IL)-1 $\beta$, IL- 6 and the expression of phosphorylated (p)-NF- $\kappa \mathrm{B}$ p65 was analyzed by western blot analysis. Lung tissues $(\sim 100 \mathrm{mg})$ were cut into small pieces and lysed in ice-cold radioimmunoprecipitation assay lysis buffer containing $50 \mathrm{mM}$ Tris ( $\mathrm{pH}=7.4), 1 \%$ Triton $\mathrm{X}-100$, $150 \mathrm{mM} \mathrm{NaCl}, 0.1 \%$ SDS, $1 \%$ sodium deoxycholate, phosphatase inhibitors and $100 \mu \mathrm{M}$ phenylmethylsulfonyl fluoride. Supernatants were prepared by centrifugation at $12,000 \mathrm{x} \mathrm{g}$ for $10 \mathrm{~min}$ at $4^{\circ} \mathrm{C}$. Protein concentration was determined using the bicinchoninic acid protein assay kit (Beyotime Institute of Biotechnology, Haimen, China). Protein extracts $(40 \mu \mathrm{g})$ were separated by 10 or $12 \%$ SDS-PAGE and transferred to polyvinylidene fluoride membranes. The membranes were blocked with 5\% nonfat dry milk in TBS with Tween-20 (10 mM Tris, $150 \mathrm{mM} \mathrm{NaCl}, 0.05 \%$ Tween-20; $\mathrm{pH}=7.5$ ) for $2 \mathrm{~h}$ at room 
temperature with constant agitation. Blocking was followed by probing with corresponding primary antibodies against IкB $\alpha$ (1:5,000; cat. no. ab32518; Abcam, Cambridge, UK), TNF- $\alpha$ (1:500; cat. no. ab7742; Abcam), COX-2 (1:1,000; cat. no. ab52237; Abcam), horseradish peroxidase (HRP)-labeled IL-1 $\beta$ (1:500; cat. no. ab106035; Abcam), IL-6 (1:1,000; cat. no. ab15690; Abcam), p-NF-кB p65 (1:2,000; cat. no. ab86299; Abcam) and HRP-labeled $\beta$-actin (1:5,000; cat. no. KC-5A08; KangChen Bio-tech, Inc., Shanghai, China) at $4^{\circ} \mathrm{C}$ overnight. Following incubation with secondary HRP-conjugated antibody $(1: 1,000$ or 1:2,000; goat anti-rabbit immunoglobulin G; cat. no. 14708; Cell Signaling Technology, Inc., Danvers, MA, USA) at room temperature for $1 \mathrm{~h}$, except (HRP)-labeled IL-1 $\beta$ and $\beta$-actin, immunoreactive proteins were visualized using the enhanced chemiluminescence western blot detection kit (Beyotime Institute of Biotechnology) and exposed to gel imaging (Bio-Rad Laboratories, Inc., Hercules, CA, USA). The images were scanned and band intensity was semi-quantified using Quantity One software (version 4.52; Bio-Rad Laboratories, Inc.).

Statistical analysis. All data were obtained according to completely randomized controlled design requirements collection. Data are presented as the mean + standard deviation. One-way analysis of variance was used to determine statistical comparisons between groups using SPSS software (version 16.0; SPSS, Inc., Chicago, IL, USA). Post hoc comparisons were performed using Fisher's least significant difference (LSD) test for equal variances, and with Dunnett's T3 for unequal variances. $\mathrm{P}<0.05$ was considered to indicate a statistically significant difference.

\section{Results}

Effects of Ost on MPAP in rats. At day 29 after MCT injection, the mPAP was measured by right heart catheterization. As demonstrated in Fig. 1, the mPAP in the MCT group was 3.0 times higher compared with the control group $(\mathrm{P}<0.05$; Fig. 1). Ost administration (10 and $20 \mathrm{mg} / \mathrm{kg}$ ) for 28 days significantly reduced the mPAP; administration of 10 and $20 \mathrm{mg} /$ Ost $\mathrm{kg}$ for 28 days decreased the mPAP by 50 and $52 \%$, respectively, compared with the MCT group ( $\mathrm{P}<0.05$; Fig. 1).

Effects of Ost on lung weight index in rats. In the MCT group, the lung weight index was significantly increased by 2.8 times compared with the control group $(\mathrm{P}<0.05$; Fig. 2$)$. Administration of Ost (10 or $20 \mathrm{mg} / \mathrm{kg}$ ) decreased lung weight index by 31 and 47\%, respectively, compared with the MCT group ( $\mathrm{P}<0.05$; Fig. 2$)$.

Effects of Ost on lung morphology. The effects of Ost treatment on MCT-induced PAH were evaluated by H\&E staining of tissue sections. As demonstrated in Fig. 3, the pulmonary artery was normal and no pulmonary interstitial inflammation was observed in the control group (Fig. 3A). Conversely, the pulmonary vessel wall was thickened, the lumen was narrow and pulmonary interstitial inflammation was evident in the MCT group (Fig. 3B). Following treatment with Ost (10 or $20 \mathrm{mg} / \mathrm{kg}$ ), the membrane structure in the pulmonary artery was improved, and the pulmonary interstitial inflammation

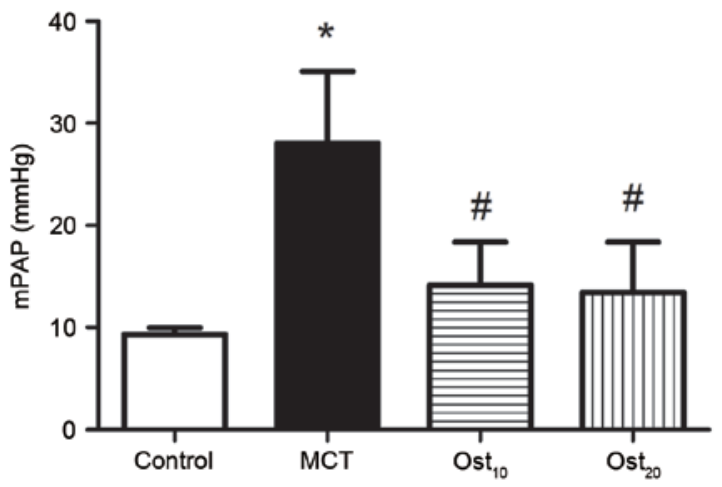

Figure 1. Effects of Ost on mPAP in MCT-induced rats. mPAP was measured by right heart catheterization. Control, solvent control group; MCT, MCT model group; Ost ${ }_{10}$, MCT with $10 \mathrm{mg} / \mathrm{kg}$ Ost; Ost ${ }_{20}$, MCT with $20 \mathrm{mg} / \mathrm{kg}$ Ost. Data are presented as the mean + standard deviation $(n=6-7) .{ }^{*} \mathrm{P}<0.05$ vs control; ${ }^{\text {P }}<0.05$ vs. MCT. Ost, osthole; MCT, monocrotaline; mPAP, mean pulmonary artery pressure.

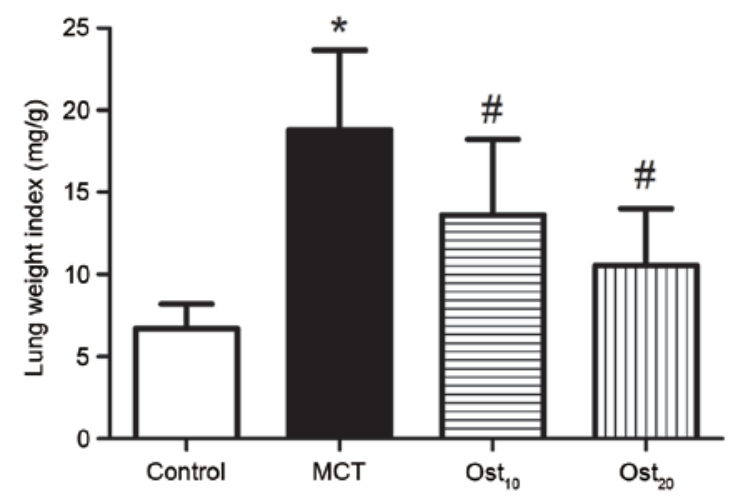

Figure 2. Effects of Ost on lung weight index in MCT-induced rats. Lung weight index was calculated as the ratio of lung weight to body weight. Control, solvent control group; MCT, MCT model group; Ost ${ }_{10}$, MCT with $10 \mathrm{mg} / \mathrm{kg}$ Ost; Ost ${ }_{20}$, MCT with $20 \mathrm{mg} / \mathrm{kg}$ Ost. Data are presented as the mean + standard deviation $(\mathrm{n}=10-11) .{ }^{*} \mathrm{P}<0.05$ vs. control; ${ }^{\#} \mathrm{P}<0.05$ vs. MCT. Ost, osthole; MCT, monocrotaline.

was reduced (Fig. 3C and D). In addition, there was a 2.6-fold increase in \%WT, an index of medial hypertrophy in the lungs calculated by Image-Pro Plus 6.0 image analysis software, in the MCT group compared with the control group for the 50-100 $\mu \mathrm{m}$ vessel size ranges, at day 29 after MCT injection. $(\mathrm{P}<0.05$; Fig. 3E). However, the \%WT was decreased by 27 and $34 \%$, respectively, in Ost treatment groups compared with in the MCT group $(\mathrm{P}<0.05$; Fig. 3E).

Effects of Ost on the protein expression levels of TNF- $\alpha$, $C O X-2, I L-1 \beta$ and $I L-6$ in the lung. In order to identify the potential molecular mechanism underlying the effects of Ost on $\mathrm{PAH}$, the protein expression of proinflammatory cytokines, including TNF- $\alpha$, COX-2, IL- $1 \beta$ and IL- 6 in the lung were determined by western blot analysis in MCT-induced rats. MCT significantly upregulated the protein expression of TNF- $\alpha$, COX-2, IL-1 $\beta$ and IL- 6 by $2.1,5.1,2.3$ and 6.1 times, respectively, compared with the control group $(\mathrm{P}<0.05$; Figs. 4 and 5). However, the expression of these proteins was decreased by $32,66,41$ and $73 \%$, respectively, when treated with Ost at $10 \mathrm{mg} / \mathrm{kg}(\mathrm{P}<0.05$; Figs. 4 and 5), and the expression of these 

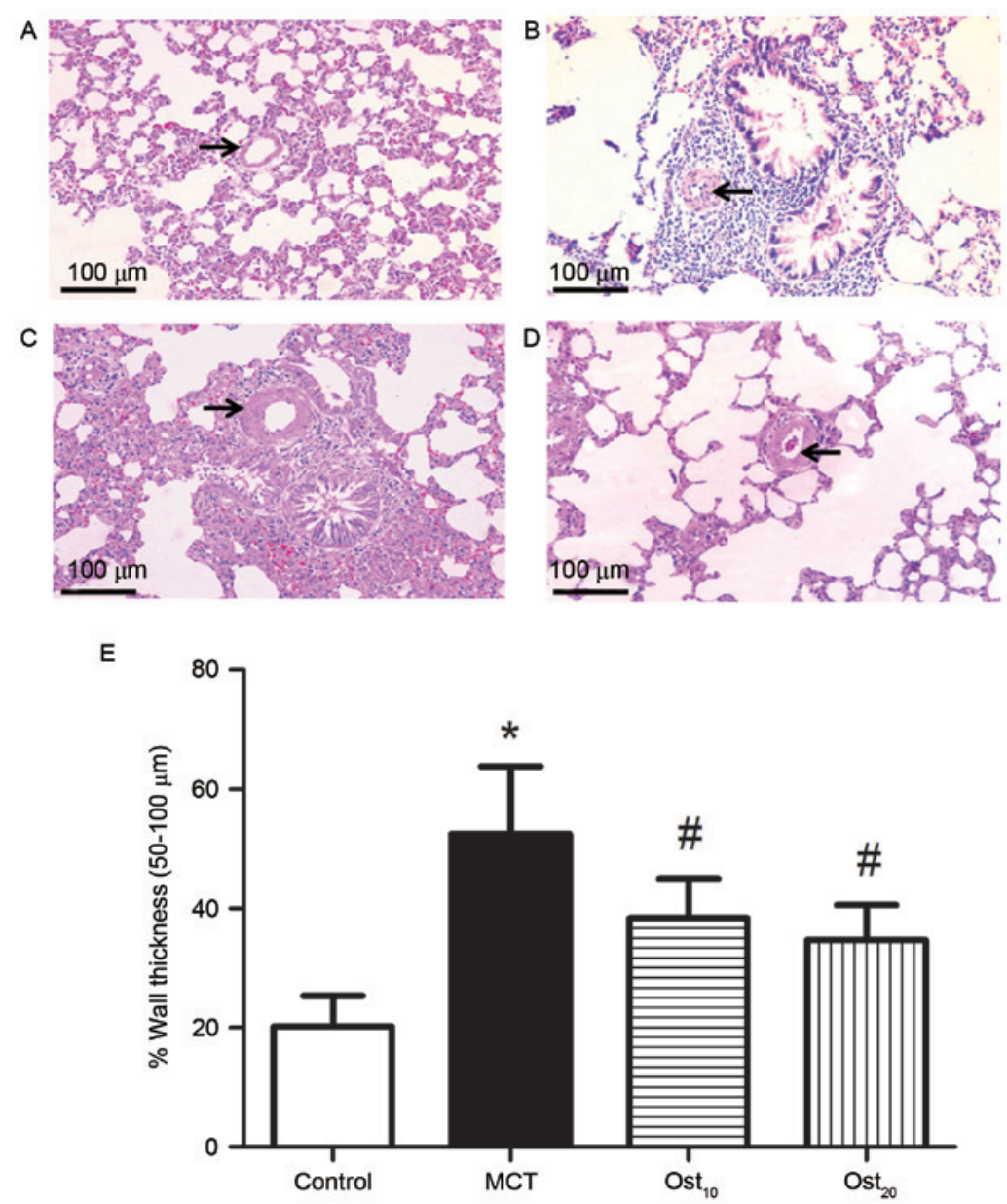

Figure 3. Effects of Ost on pathological alterations in the pulmonary artery in MCT-induced rats. Arrows represent the pulmonary artery in (A) control, (B) MCT, (C) Ost ${ }_{10}$ and (D) Ost 20 groups. (E) Percentage WT was calculated for each group for arteries between 50 and $100 \mu \mathrm{m}$ in external diameter. The external diameter and WT were measured by Image-Pro Plus 6.0 image analysis software. Control, solvent control group; MCT, MCT model group; Ost 10 , MCT with $10 \mathrm{mg} / \mathrm{kg}$ Ost; Ost ${ }_{20}$, MCT with $20 \mathrm{mg} / \mathrm{kg}$ Ost. Data are presented as the mean + standard deviation $(\mathrm{n}=6-7) .{ }^{*} \mathrm{P}<0.05$ vs. control; ${ }^{\# P} \mathrm{P}<0.05 \mathrm{vs}$. MCT. Ost, osthole; MCT, monocrotaline; WT, wall thickness.
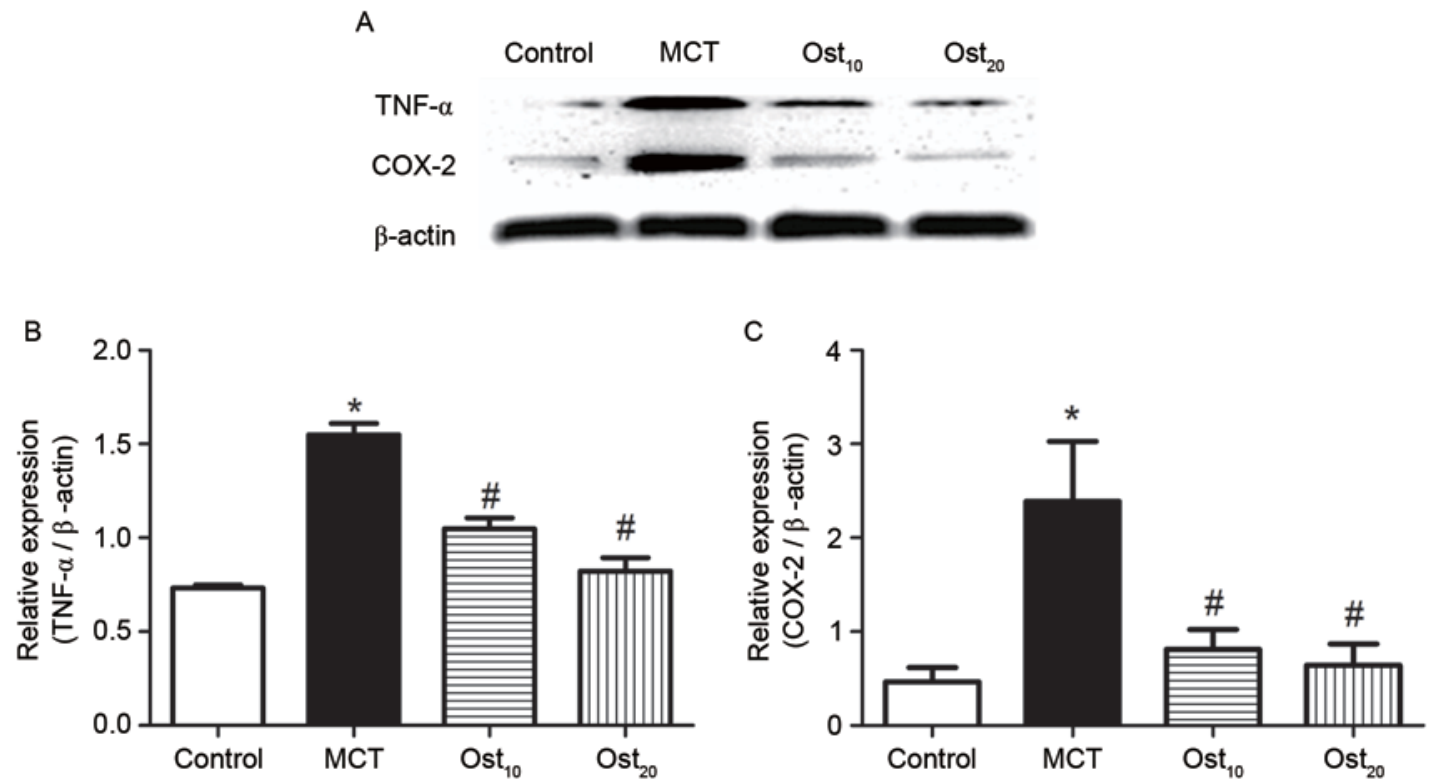

Figure 4. Effects of Ost on the expression of TNF- $\alpha$ and COX-2 proteins in MCT-induced rats. The protein expression levels of TNF- $\alpha$ and COX-2 were determined by western blot analysis. (A) Representative western blot of TNF- $\alpha$ and COX-2 proteins for control, MCT, Ost ${ }_{10}$, and Ost ${ }_{20}$ groups. Semi-quantification of the relative expression of (B) TNF- $\alpha$ and (C) COX-2 proteins in each group. Control, solvent control group; MCT, MCT model group; Ost ${ }_{10}$, MCT with $10 \mathrm{mg} / \mathrm{kg}$ Ost; Ost ${ }_{20}$, MCT with $20 \mathrm{mg} / \mathrm{kg}$ Ost. Data are presented as the mean + standard deviation $(\mathrm{n}=4) .{ }^{*} \mathrm{P}<0.05$ vs. control; ${ }^{\text {} P}<0.05$ vs. MCT. Ost, osthole; TNF- $\alpha$, tumor necrosis factor- $\alpha$; COX-2, cyclooxygenase-2; MCT, monocrotaline. 


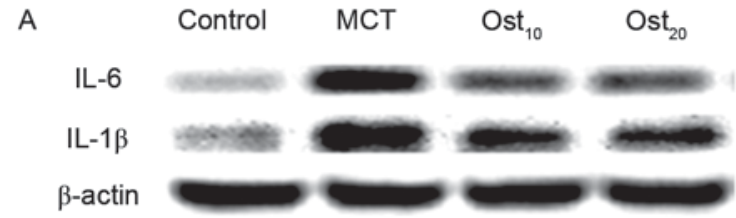

B

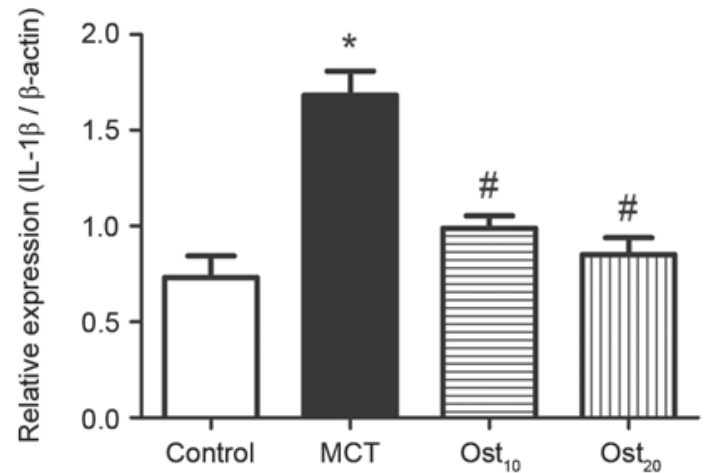

C

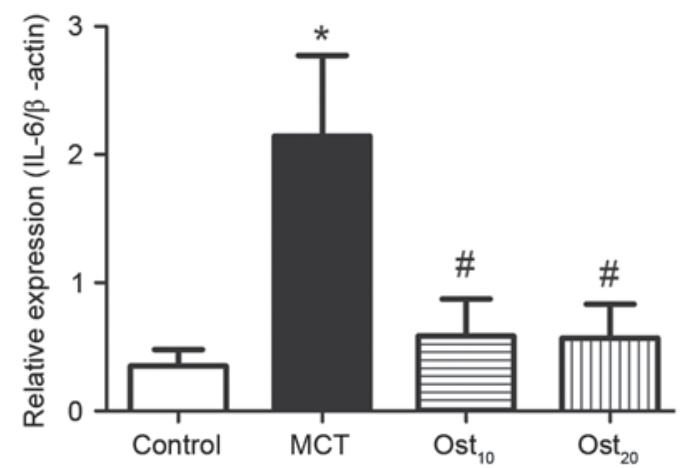

Figure 5. Effects of Ost on the expression of IL-1 $\beta$ and IL-6 proteins in MCT-induced rats. The protein expression levels of IL-1 $\beta$ and IL-6 were detected by western blot analysis. (A) Representative western blot of IL-1 $\beta$ and IL-6 proteins for control, MCT, Ost ${ }_{10}$, and Ost ${ }_{20}$ groups. Semi-quantification of the relative expression of (B) IL-1 $\beta$ and (C) IL-6 proteins in each group. Control, solvent control group; MCT, MCT model group; Ost ${ }_{10}$, MCT with $10 \mathrm{mg} / \mathrm{kg}$ Ost; Ost ${ }_{20}$, MCT with $20 \mathrm{mg} / \mathrm{kg}$ Ost. Data are presented as the mean + standard deviation $(\mathrm{n}=4) .{ }^{*} \mathrm{P}<0.05 \mathrm{vs}$. control; " $\mathrm{P}<0.05 \mathrm{vs}$. MCT. Ost, osthole; IL, interleukin; MCT, monocrotaline.

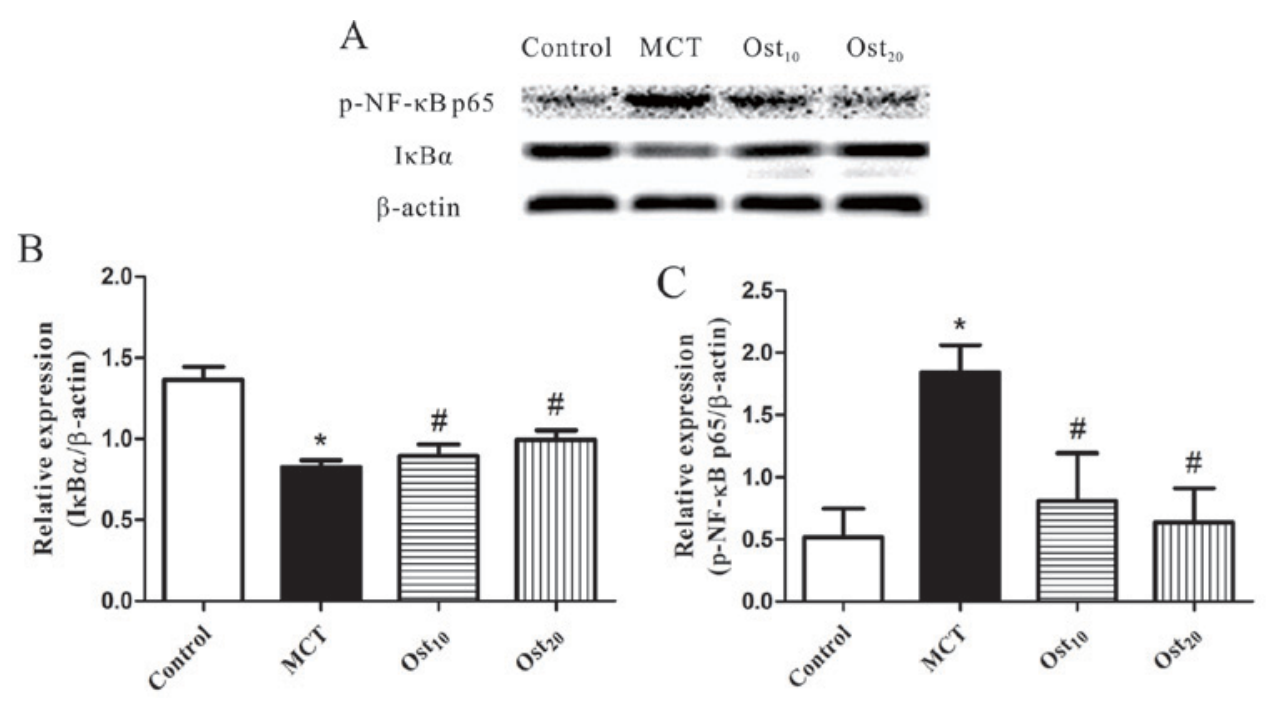

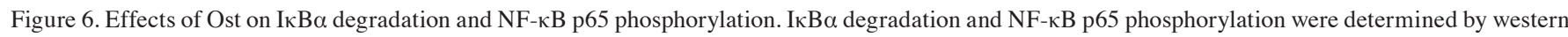

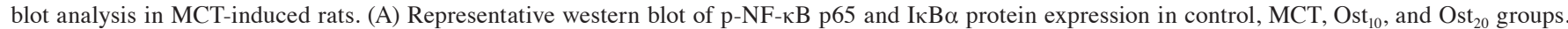
Semi-quantification of the relative expression of (B) IкB $\alpha$ and (C) p-NF-кB p65. Control, solvent control group; MCT, MCT model group; Ost ${ }_{10}$, MCT with $10 \mathrm{mg} / \mathrm{kg}$ Ost; Ost ${ }_{20}$, MCT with $20 \mathrm{mg} / \mathrm{kg}$ Ost. Data are presented as the mean + standard deviation $(\mathrm{n}=4) .{ }^{*} \mathrm{P}<0.05$ vs. control; " $\mathrm{P}<0.05$ vs. MCT. Ost, osthole;

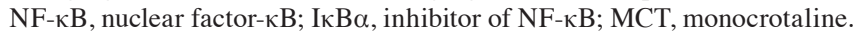

proteins was further downregulated by $47,73,49$ and $73 \%$, respectively, when treated with $20 \mathrm{mg} / \mathrm{kg}$ Ost, compared with the MCT group ( $\mathrm{P}<0.05$; Figs. 4 and 5). These results indicated that Ost inhibited the overexpression of TNF- $\alpha, \mathrm{COX}-2$, IL-1 $\beta$ and IL-6 proteins in the lung of the MCT-induced rats.

Effects of Ost on I $\kappa \mathrm{B} \alpha$ degradation and $\mathrm{NF}-\kappa \mathrm{B}$ p 65 phosphorylation. To further determine the mechanism underlying the inhibitory effects of Ost on the expression of proinflammatory cytokines, I $\kappa \mathrm{B} \alpha$ degradation and NF- $\kappa \mathrm{B}$ p 65 phosphorylation were detected by western blot analysis. As demonstrated in Fig. 6, compared with the control group, I $\mathrm{B} \alpha$ protein expression in the MCT group was reduced by $40 \%$ ( $\mathrm{P}<0.05$; Fig. 6). However, it was demonstrated that $\mathrm{I} \kappa \mathrm{B} \alpha$ protein expression was upregulated in groups treated with 10 and $20 \mathrm{mg} / \mathrm{kg}$ Ost by 8.6 and $20.6 \%$, respectively, compared with the MCT group $(\mathrm{P}<0.05$; Fig. 6), indicating the suppression of MCT-induced $\mathrm{I} \kappa \mathrm{B} \alpha$ degradation by Ost. The expression of $\mathrm{p}-\mathrm{NF}-\kappa \mathrm{B}$ p65 in the MCT group was elevated by 3.6 times, compared with the control group $(\mathrm{P}<0.05$; Fig. 6$)$, whereas treatment with Ost $(10$ 
or $20 \mathrm{mg} / \mathrm{kg}$ ) caused a decrease in the MCT-induced NF- $\mathrm{kB}$ p65 phosphorylation by 56 and $65 \%$, respectively $(\mathrm{P}<0.05 ;$ Fig. 6$)$.

\section{Discussion}

Administration of a single injection of MCT in rats is a well-defined model in which the animals subsequently develop severe PAH $(22,23)$. This model is considered one of the most effective animal models used to investigate the pathological development of PAH. The pathological development and the disease severity of the animals in this model are comparable to those of human PAH (22). Previous studies have demonstrated that MCT is converted to MCT-pyrrole in the liver, which in turn causes endothelial cell injury followed by increased infiltration of mononuclear cells into the perivascular regions of arterioles and muscular arteries (22-24), which has an important role in the development of PAH in humans (25). The present study demonstrated that the mPAP and the lung weight index were significantly increased, the pulmonary artery membrane was thickened, the lumen was narrow and interstitial inflammation was observed in rats treated with MCT. The results indicated that the MCT-induced PAH model was successfully established. Following Ost administration, the mPAP and the lung weight index were significantly decreased, the thickening of pulmonary arteries was markedly reduced, the lumen widened and interstitial inflammation was reduced, compared with the MCT group. These results indicated that Ost may exhibit anti-PAH effects.

Previous studies have reported that IL-1 $1 \beta$, IL- 6 and TNF- $\alpha$ damage pulmonary artery endothelial cells, cause abnormal pulmonary artery smooth muscle cell proliferation and prevent apoptosis, leading to pulmonary arterial remodeling and the promotion of PAH development $(3,7)$. Previous studies have demonstrated that the expression levels of TNF- $\alpha$, IL- $1 \beta$ and IL-6 are significantly increased in MCT-induced PAH $(26,27)$, and IL- $1 \beta$ and IL- 6 promoted pulmonary artery smooth muscle cell proliferation and/or induced vascular intima migration (7). Furthermore, the mRNA and protein expression levels of COX-2 were significantly upregulated in the combination of left pneumonectomy with MCT-treated PAH (28). Notably, these important inflammatory mediators are all under regulation by NF- $\kappa B$.

$\mathrm{NF}-\mathrm{kB}$ is a transcription factor that regulates inflammation and immune responses. It has an important role in transcriptional activation, cell proliferation and migration; therefore, it is regarded as the 'total switch' of inflammatory reactions (29). Under physiological conditions, NF- $\mathrm{KB}$ p65/p50 binds to its inhibitory protein I $\mathrm{KB}$ in the cytoplasm. When subjected to mechanical stress, viruses, oxidant attack and inflammatory factor stimulation, $\mathrm{I} \kappa \mathrm{B} \alpha$ kinase is activated to induce I $\mathrm{B} \alpha$ phosphorylation and degradation. Phosphorylation of the I $\mathrm{K} \mathrm{B} \alpha$ inhibitory protein and its subsequent degradation by a proteasome-dependent pathway results in activation of NF- $\kappa B$. Phosphorylated p65/p50 rapidly migrates from the cytoplasm to the nucleus (particularly the p65 subtype). Subsequently, phosphorylated p65/p50 combines with the $\mathrm{\kappa B}$ site of the DNA chain to trigger an inflammatory cascade, which induces the transcription of various inflammatory cytokines, thus promoting cell proliferation and suppressing the apoptotic pathway, leading to the occurrence and development of PAH $(30,31)$.

Previous studies have demonstrated that Ost exhibits anti-inflammatory and antibacterial functions, and enhances immunity $(15,16)$. It has been reported that Ost significantly downregulates the expression of NF-кB p65, TNF- $\alpha$, IL- $1 \beta$ and IL-6 in lipopolysaccharide-stimulated 3T3-L1 adipocytes or carrageenan-induced lung inflammation in rats, and also in inflammation induced by renal ischemia-reperfusion in rats $(19,20,32)$. The results of the present study demonstrated that the protein expression levels of I $\mathrm{B} \alpha$ were downregulated, and the levels of p-NF- $\mathrm{kB}$ p65 and the protein expression of IL- $1 \beta$, IL- 6 , TNF- $\alpha$ and COX- 2 were upregulated in the lungs of MCT-treated rats. These results indicated that the progression of PAH may be associated with activation of the NF- $\kappa B$ p65 signaling pathway. The protein expression levels of I $\kappa \mathrm{B} \alpha$ were significantly upregulated, and the levels of p-NF- $\kappa \mathrm{B}$ p65 and the protein expression of IL- $1 \beta$, IL-6, TNF- $\alpha$ and COX-2 were downregulated in lung tissue following Ost treatment, compared with rats treated with MCT only. These findings suggested that inhibition of the NF- $\mathrm{NB}$ p65 pathway may be considered to be the potential mechanism underlying the Ost-induced downregulation of inflammatory factors in a rat model of MCT-induced PAH.

In conclusion, the present study demonstrated that the NF- $\mathrm{BB}$ p65 signaling pathway serves an important role in the development of PAH, and Ost may confer protection against MCT-induced PAH, which may be mediated through suppression of MCT-induced production of TNF- $\alpha, \mathrm{COX}-2$, IL-1 $\beta$ and IL-6, at least partially, by inhibiting MCT-induced I $\mathrm{B} \alpha$ degradation and subsequent activation of NF- $\kappa \mathrm{B}$ p 65 . Based on the results observed in the current study, Ost may have the potential to be developed for the treatment of PAH. Future studies are required to further observe the underlying mechanism of PAH associated with endoplasmic reticulum stress and apoptosis.

\section{Acknowledgements}

The present study was supported by grants from the National Natural Science Foundation of China (grant no. 81360498) and the Provincial Special Funds for Outstanding Technological and Educational Talents in Guizhou, China [grant no. Qian Sheng Zhuan He Zi (2012) 93].

\section{References}

1. Archer SL, Weir EK and Wilkins MR: Basic science of pulmonary arterial hypertension for clinicians: New concepts and experimental therapies. Circulation 121: 2045-2066, 2010.

2. Nakata TM, Tanaka R, Yoshiyuki R, Fukayama T, Goya S and Fukushima R: Effects of single drug and combined short-term administration of sildenafil, pimobendan, and nicorandil on right ventricular function in rats with monocrotaline-induced pulmonary hypertension. J Cardiovasc Pharmacol 65: 640-648, 2015.

3. Rabinovitch M, Guignabert C, Humbert M and Nicolls MR: Inflammation and immunity in the pathogenesis of pulmonary arterial hypertension. Circ Res 115: 165-175, 2014.

4. Ahmed LA, Obaid AA, Zaki HF and Agha AM: Role of oxidative stress, inflammation, nitric oxide and transforming growth factor-beta in the protective effect of diosgenin in monocrotaline-induced pulmonary hypertension in rats. Eur J Pharmacol 740: 379-387, 2014. 
5. White RJ and Morrell NW: Understanding the low penetrance of bone morphogenetic protein receptor 2 gene mutations: Another needle in the haystack. Circulation 126: 1818-1820, 2012.

6. Sutendra G, Dromparis P, Bonnet S, Haromy A, McMurtry MS, Bleackley RC and Michelakis ED: Pyruvate dehydrogenase inhibition by the inflammatory cytokine $\mathrm{TNF} \alpha$ contributes to the pathogenesis of pulmonary arterial hypertension. J Mol Med (Berl) 89: 771-783, 2011.

7. Hassoun PM, Mouthon L, Barberà JA, Eddahibi S, Flores SC, Grimminger F, Jones PL, Maitland ML, Michelakis ED, Morrell NW, et al: Inflammation, growth factors, and pulmonary vascular remodeling. J Am Coll Cardiol 54 (1 Suppl): S10-S19, 2009.

8. Sen R and Baltimore D: Inducibility of kappa immunoglobulin enhancer-binding protein Nf-kappa B by a posttranslational mechanism. Cell 47: 921-928, 1986.

9. Kimura H, Okada O, Tanabe N, Tanaka Y, Terai M, Takiguchi Y, Masuda M, Nakajima N, Hiroshima K, Inadera H, et al: Plasma monocyte chemoattractant protein-1 and pulmonary vascular resistance in chronic thromboembolic pulmonary hypertension. Am J Respir Crit Care Med 164: 319-324, 2001.

10. Hoeper MM, Schwarze M, Ehlerding S, Adler-Schuermeyer A, Spiekerkoetter E, Niedermeyer J, Hamm M and Fabel H: Long-term treatment of primary pulmonary hypertension with aerosolized iloprost, a prostacyclin analogue. N Engl J Med 342: 1866-1870, 2000.

11. Wilkins MR, Ali O, Bradlow W, Wharton J, Taegtmeyer A, Rhodes CJ, Ghofrani HA, Howard L, Nihoyannopoulos P, Mohiaddin RH, et al: Simvastatin as a treatment for pulmonary hypertension trial. Am J Resp Crit Care Med 181: 1106-1113, 2010.

12. Galié N, Ghofrani HA, Torbicki A, Barst RJ, Rubin LJ, Badesch D, Fleming T, Parpia T, Burgess G, Branzi A, et al: Sildenafil citrate therapy for pulmonary arterial hypertension. N Engl J Med 353: 2148-2157, 2005.

13. Benza RL, Miller DP, Barst RJ, Badesch DB, Frost AE and McGoon MD: An evaluation of long term survival from time of diagnosis in pulmonary arterial hypertension from the REVEAL Registry. Chest 142: 448-456, 2012.

14. Zhang ZR, Leung WN, Cheung HY and Chan CW: Osthole: A review on its bioactivities, pharmacological properties, and potential as alternative medicine. Evid Based Complement Alternat Med 2015: 919616, 2015.

15. Liao PC, Chien SC, Ho CL, Wang EI, Lee SC, Kuo YH, Jeyashoke N, Chen J, Dong WC, Chao LK and Hua KF: Osthole regulates inflammatory mediator expression through modulating $\mathrm{NF}-\kappa \mathrm{B}$, mitogen-activated protein kinases, protein kinase $\mathrm{C}$, and reactive oxygen species. J Agric Food Chem 58: 10445-10451, 2010.

16. Zhang XP, Chen XM, Cui QH and Tian JZ: Studies on pharmacological activity and mechanism of osthole. China Licensed Pharmacist 11: 28-32, 2013.

17. You L, Feng S, An R and Wang X: Osthole: A promising lead compound for drug discovery from a traditional Chinese medicine (TCM). Nat Prod Commun 4: 297-302, 2009.

18. Wang R, Kong J, Wang D, Lien LL and Lien EJ: A survey of Chinese herbal ingredients with liver protection activities. Chin Med 2: 5, 2007.
19. Li Z, Ji H, Song X, Hu J, Han N and Chen N: Osthole attenuates the development of carrageenan-induced lung inflammation in rats. Int Immunopharmacol 20: 33-36, 2014.

20. Zheng Y, Lu M, Ma L, Zhang S, Qiu M and Ma X: Osthole ameliorates renal ischemia-reperfusion injury by inhibiting inflammatory response. Urol Int 91: 350-356, 2013.

21. O'Blenes SB, Fischer S, McIntyre B, Keshavjee S and Rabinovitch M: Hemodynamic unloading leads to regression of pulmonary vascular disease in rats. $\mathbf{J}$ Thorac Cardiovase Surg 121: 279-289, 2001.

22. Nogueira-Ferreira R, Vitorino R, Ferreira $R$ and Henriques-Coelho T: Exploring the monocrotaline animal model for the study of pulmonary arterial hypertension: A network approach. Pulm Pharmacol Ther 35: 8-16, 2015.

23. Campian ME, Hardziyenka M, Michel MC and Tan HL: How valid are animal models to evaluate treatments for pulmonary hypertension? Naunyn Schmiedebergs Arch Pharmacol 373: 391-400, 2006.

24. Nishimura T, Faul JL, Berry GJ, Veve I, Pearl RG and Kao PN: 40-O-(2-hydroxyethyl)-rapamycin attenuates pulmonary arterial hypertension and neointimal formation in rats. Am J Respir Crit Care Med 163: 498-502, 2001.

25. Rey M, Hess P and Clozel M: Monocrotaline-induced pulmonary hypertension in Wistar rats. Curr Protoc Pharmacol Chapter 5: Unit 5.56, 2009.

26. Liu C, Fang C, Cao G, Liu K, Wang B, Wan Z, Li S and Wu S: Ethyl pyruvate ameliorates monocrotaline-induced pulmonary arterial hypertension in rats. J Cardiovasc Pharmacol 64: 7-15, 2014.

27. Wang $\mathrm{X}$, Wang $\mathrm{Y}$, Rong $\mathrm{S}$ and $\mathrm{Ma} \mathrm{H}$ : Early treatment with hepatocyte growth factor improves pulmonary artery and right ventricular remodeling in rats with pulmonary artery hypertension by modulating cytokines expression. Zhonghua Jie $\mathrm{He} \mathrm{He}$ Hu Xi Za Zhi 37: 427-432, 2014 (In Chinese).

28. Liu ZQ, Liu B, Yu L, Wang XQ, Wang J and Liu HM: Effect of simvastatin on expression of cyclooxygenase- 2 in a rat model of pulmonary artery hypertension. Chin Heart J 21: 625-628, 2009.

29. Lee TL, Yeh J, Friedman J, Yan B, Yang X, Yeh NT, Van Waes C and Chen Z: A signal network involving coactivated NF-kappaB and STAT3 and altered p53 modulates BAX/BCL-XL expression and promotes cell survival of head and neck squamous cell carcinomas. Int J Cancer 122: 1987-1998, 2008.

30. Hoffmann A, Levchenko A, Scott ML and Baltimore D: The IkappaB-NF-kappa B signaling module: Temporal control and selective gene activation. Science 298: 1241-1245, 2002

31. Ogawa A, Firth AL, Yao W, Rubin LJ and Yuan JX: Prednisolone inhibits PDGF-induced nuclear translocation of NF-kappaB in human pulmonary artery smooth muscle cells. Am J Physiol Lung Cell Mol Physiol 295: L648-L657, 2008.

32. Wang XL, Shang X, Cui Y, Zhao X, Zhang Y and Xie ML: Osthole inhibits inflammatory cytokine release through PPAR $\alpha /$ $\gamma$-mediated mechanisms in LPS-stimulated 3T3-L1 adipocytes. Immunopharmacol Immunotoxicol 37: 185-192, 2015. 